\title{
Environmental Assessment of Energy Related Products and Energy Systems Across Their Life Cycle
}

\author{
N. Espinosa and Y. J. Suh
}

\begin{abstract}
In a global context, where several international and national policies attempt to define strategic energy plans that address environmental sustainability, it is necessary to adopt a holistic perspective. In this session, we want to stimulate inputs on how Life Cycle Assessment (LCA) models can capture the complex management challenges in the whole energy sector. In that sense, the various sectors related to energy (namely heat, power, etc.) will become more interrelated, which will be challenging to deal with in Life Cycle Management (LCM). The next decades, LCM modelling of energy systems will have to be quite innovative in order to create realistic models. Furthermore, if LCA wants to do real LCM, the methodology should be widened to e.g. include long-term environmental implications.
\end{abstract}

\section{Introduction}

In the global energy context, where several international and national policies attempt to define strategic energy plans that address environmental sustainability, it is necessary to adopt a holistic perspective.

A comprehensive quantification of environmental impacts in the energy sector can be done by means of Life Cycle Assessment (LCA). Current developments in energy systems and energy products are limited in their scopes with strong focus on greenhouse gas accountings with disregard for other environmental problems like the impacts of chemical pollution and particulate matters on human health and ecosystems. The session aims to address the importance of rooting environmental sustainability assessments with broad impact coverage into energy planning to

\footnotetext{
N. Espinosa $(\square)$

European Commission, Joint Research Centre, Inca Garcilaso s/n,

41092 Seville, Spain

e-mail: nieves.espinosa@ec.europa.eu

Y. J. Suh

Samsung Electronics Co., Ltd., Suwon, Korea

(C) The Author(s) 2018

E. Benetto et al. (eds.), Designing Sustainable Technologies,

Products and Policies, https://doi.org/10.1007/978-3-319-66981-6_25
} 
prevent or minimise problem shifting and ensure an environmentally-sound energy transition.

Other than environmental factors such as costs, politics, regional interdependencies, risks, or social issues, an energy transition will have to be furthermore addressed in true Life Cycle Management (LCM) models of future energy supply.

The topics included in the session were the following:

- How to address emerging energy technologies in LCA, e.g. carbon capture and storage (CCS), etc.

- Integration of the ecodesign directive in energy-related products and technologies

- Inclusion of foresight and dynamic aspects in applications of LCA to energy systems

- Barriers and solutions in application of LCA to energy systems, e.g. modelling challenges such as temporal and geographical resolution versus data availability and level of detail of results needed

- Handling of bioenergy (poses specific methodological challenges, e.g. iLUC)

- Relevance of transportation in LCA energy systems

The objective of the session was to discuss and advance the implementation of Life Cycle approach and Circular Economy along the businesses value chain, supporting environmental, social and economic sustainability related to the development of industrial technologies, products, services and policies.

The session was proposed in synergy with a parallel session conducted at the LCM 2017 conference on LCM of energy and energy transitions. In this session, we wanted to stimulate inputs on how LCA models can capture the complex management challenges in the whole energy sector. In that sense, the various sectors related to energy (namely heat, power, etc.) have become more interrelated, which will be challenging to deal with in LCM. Therefore, the next decades, LCM modelling of energy systems will have to be quite innovative in order to create realistic models. Furthermore, if LCA wants to do real LCM, the methodology should be widened to e.g. include long-term environmental implications.

\section{Summary of the Session Presentations}

The session proposed had the aim to highlight the importance of rooting environmental sustainability assessments with broad impact coverage into energy planning.

The presentations had in general an outstanding quality. Data availability and level of detail of results needed was a topic proposed. Life cycle inventories of good quality are essential to conduct any study and there were a number of presentations dealing with that topic.

Oberschelp et al. [1] deal in their work with other case of data availability: the emission of particulate matter from the production of electricity in China. A detailed 
inventory for Chinese power production from fossil fuels was developed and combined with characterization factors for Chinese particulate matter emission impacts.

Moreover, the geographical resolution of the data may indeed reveal big differences in environmental impacts of energy production, and this is precisely presented in a contribution targeting the LCI data for electricity production at smaller geographic regions of both China and India by Levova et al. [2]

The full coverage of impacts and the comprehensiveness of LCA for energy systems were two topics dealt with in the work presented by Chatzsisideris et al. [3] about quantifying the importance of comprehensive life cycle and impact coverage for photovoltaic systems.

In the same field, the PV systems, Weyand et al. [4] show in their work for a portable solar charger how consequential LCA modelling can extend the boundaries to consider indirect impacts associated with the materials and energy use and the function the product delivers, which has so far been neglected in assessment efforts for an emerging technology such as organic photovoltaics.

The LCA study of a mobile phone charger incorporating $20 \%$ recycled plastic made by $\mathrm{Heo}$ et al. from Samsung Electronics [5], covers each life cycle stage including pre-manufacturing, manufacturing, use and disposal phase. The study shows that the use phase is the most significant life cycle stage due to the impact on global warming resulting from charging the phone.

For a sustainable production of plastics Himmelreich [6] illustrates the development of $\mathrm{CO}_{2}$ based plastics and the implementation into consumer products as well as discuss the influence of different $\mathrm{CO}_{2}$ sources and their impact dependent on the valuation method for $\mathrm{CO}_{2}$.

Van Nieuwenhuyse et al. [7] propose a work related to resource efficiency and the development of extended producer responsibility schemes that are fostering the development of updated and accurate Life Cycle Inventories (LCI) data on end-of-life operations. A consortium of companies have joint efforts to develop a LCI database of Waste Electrical and Electronic Equipment (WEEE).

About the usage of energy consuming product, Heslouin et al. [8] propose to improve the modelling of the use scenario to improve the environmental footprint. The challenge here is the data availability to model specific scenarios for each use case.

Improving energy efficiency is one of the main topics of the European 2020 strategy [9]. The building sector consumes $40 \%$ of the total energy whereby the major part is being used for space heating where the energy is quickly lost to the environment. This loss could be significantly counterbalanced in the future by the development of multi-functional energy-efficient windows or façades, designed to produce energy from sunlight and to store heating energy. New energy efficient window design accompanying LCA (and cost considerations) are proposed to be integrated in the overall development process right from the start by Schmidt et al. [10]. 


\section{Analysis and Outcomes of the Session}

The problem of particulate matter impacts from energy production in China had not been assessed on a high regional resolution due to a lack of a site-specific technology-linked inventory for emissions. Oberschelp et al. have developed a detailed inventory for Chinese power production derived from the International Energy Agency's coal power atlas and the PLATTS World electric power plant (WEPP) database. Remaining gaps in the inventory were filled with global US Geological Survey (USGS) fossil fuel data. A combustion model was moreover applied to quantify outputs of the main pollutants contributing to particulate matter formation ( $\mathrm{PM} 2.5, \mathrm{NO}_{\mathrm{x}}, \mathrm{SO}_{2}$ ). Flue gas cleaning is included by taking into account technology-specific cleaning rates. These emissions were multiplied by regional characterization factors for all global cities with more than 100,000 inhabitants and characterization factor recommendations by the UNEP SETAC Life Cycle Initiative. Results and conclusions have been drawn from the country-level PM characterization factors provided by LC-Impact. Impacts were put into perspective by comparing them with other sectors (transport, industry, domestic coal combustion) in China [1].

With regard to the comprehensiveness of a LCA study, the ISO 14040 principles establish that such a study should consider the entire life cycle of the system and assess all relevant impacts on the natural environment, human health and resources. This is important in order to be able to identify and evaluate potential shifting of environmental burdens or trade-offs between life cycle stages or impact categories. However, according to Chatzsisideris et al. existing review papers of LCA on photovoltaic systems tend to exclusively focus on greenhouse gas assessments disregarding other impacts on human health and ecosystems and eluding an explicit description of which parts of the PV life cycle were considered by the LCA studies under review. Hotspots may not be properly identified if there is not a full coverage of impact categories. The analysis of Chatzsisideris showed that only a third of the analysed contributions were including the balance of system (BOS) components (i.e. power electronics, wiring, mounting structures) in their assessments, which has been proved to contribute significantly to most environmental impact categories [3].

The use of consequential LCA modelling was performed by Weyand et al. [4], to evaluate the environmental response of a phone charger made of an emerging technology such as organic photovoltaics. The impacts of an OPV charger associated with "an additional $10 \mathrm{Wh}$ electricity generation for charging phones" as functional unit, were calculated and compared them to possible substituted conventional energy generation technologies and country-specific electricity mixes. Based on the assumptions, that charging the mobile phone with an OPV charger reduces electricity at the grid, substitution scenarios of several European countries are analysed. The environmental responses of these scenarios are modelled within the software OpenLCA and analysed for the impact categories using the ReCiPe Midpoint $(\mathrm{H})$ method. Current substitution scenarios of the electricity mixes of France and Germany assume that the substituted electricity is nuclear power and 
electricity from lignite - mainly due to the high share of these energy sources in the electricity mixes. The preliminary results indicate considerable environmental benefits in the case of the OPV charger in 7 of the 18 ReCiPe impact categories. In particular, the reductions take place in categories like toxicity (freshwater, human, and marine) and eutrophication (freshwater, marine). In 8 of the 18 impact categories, the electricity generated by the OPV charger has lower impacts than one of the country-specific electricity mixes, mostly than the German scenario. For example, the OPV charger mitigates the climate change potential compared to German scenario significantly, whereas the French scenario still has the lowest impacts due to the high share of nuclear energy. Just in three impact categories, the OPV charger seems to have higher impacts than both scenarios.

For a conventional phone charger, however, key components were identified in the pre-manufacturing stage by Heo et al. [5]. These are the printed circuit board and the plastic case composed from $20 \%$ recycled poly carbonate (PC). The study compared the global warming potential (GWP) for both recycled PC and virgin PC. The result shows that recycled PC is clearly beneficial: the GWP is $96 \%$ less. The amount of GHG emission of the mobile charger containing $20 \%$ recycled plastics is $1.9648 \mathrm{~kg} \mathrm{CO}_{2}$ which is $0.089 \mathrm{~kg} \mathrm{CO}_{2}$ less than a conventional charger containing virgin plastics. A $10 \%$ increase of recycled PC contents in the charger results in $0.3 \%$ GHG-reduction across the total life cycle.

After launching the first industrial-scale production plant for polyols containing about 20 percent $\mathrm{CO}_{2}$, possible thanks to the development of a catalyst which was able to reduce the activation energy of $\mathrm{CO}_{2}$, Himmelreich did an LCA on the process. The evaluation the environmental impact of these new polyols showed that the result will be dependent on the chosen source of $\mathrm{CO}_{2}$ (e.g. biogenic, natural sources, power plants or ammonia plants) and the assumed burden of the carbon dioxide [6].

Eco-systèmes and other leading companies in take-back schemes approved by the French authorities are working on collecting and recycling WEEE. They represent several thousand producers. The database on WEEE management by Van Nieuwenhuyse et al. may contribute to solve several challenges faced by producers to adopt a circular approach, from an environmental assessment perspective, notably by:

- reducing the dissymmetry between production and end-of-life modelling, in terms of reliability and granularity of the data used;

- facilitating the modelling of a life-cycle stage which is generally not managed by material producers nor product manufacturers, and involves multi-step and multi-actor pathways;

- taking into account, on the basis of field data, the environmental benefits of material and energy recovery.

A LCI database has been developed to couple material with WEEE categories. Thereby, the database allows to take the complete recycling chain into account and 
to adapt the assessment specifically to the product design, without requiring any additional hypothesis or settings than the product material composition [7].

The usage of products is frequently modelled by average scenarios of use in LCAs. One challenge of the modelling is the data availability to model the specific scenario of each case of use. The modelling needs to collect several data can be expensive and time consuming to collect a lot of specific data to improve the modelling of the use phase. The case study of the work from Heslouin et al. is a truck refrigeration unit for which the most impactful phase is the use phase. The energy consumption depends on good and bad practice of use [8].

In the framework of the European collaborative project LAWIN, a transparent heat transfer fluid is integrated in a newly designed glass module to make use of temperature differences for energy generation. This energy shall be used directly for heating or cooling processes in the building. Optimization of the overall concept ensures that additional costs in the manufacturing phase and thus, the selling price, are kept in the range of established window or façade elements in order to ensure a quick and broad acceptance of the product building. Selected outcomes of this anticipatory evaluation comparing, e.g., different positions of the LAWIN module in windows or facades, its application as collector or as heat exchanger for heat pumps, or its use for heating or cooling show a strong dependence from the regional location in the use phase [10].

\section{Future Perspectives in Light of the Presentations}

The industrialized and densely populated Eastern parts of China around the provinces Hebei and Shandong and the municipalities Beijing, Tianjin, and Shandong heavily suffer from PM emissions. Despite recent efforts in the introduction of strict emission limits, further upgrade of flue gas treatment in power plants is necessary to reduce health issues. The closure of inefficient power plants, fuel replacement and relocation of emissions are promising options for improvement [1].

The assessment of the results for the different regions in China and India proved that there are indeed big differences in environmental impacts of energy production. Therefore, further discussion can be thus initiated whether more regions should be sub-divided or whether there is a tipping point at which further detail will not bring any additional value [2].

In order to make a comprehensive study and be able to identify hotspots with lower uncertainty, it is recommended that LCA practitioners performing LCA on PV systems consider the entire PV life cycle, including the BOS, and all relevant impact categories. In that way ecodesign opportunities can be identified without risking potential shifting of environmental burden from one part of the life cycle to another or from one impact category to another [3]. 
There is a significant potential in using OPV chargers to mitigate impacts that dominate number of impact categories, especially in regions heavily dependent on coal powered electricity such as Germany. Further analysis needs to be done to include also electricity mixes from other European countries and to understand the reasons behind the differences [4].

Whether to include recycled materials in a conventional mobile phone charger or not has been shown as clearly beneficial according to Heo et al. [5].

More environmentally sustainable plastics could further reduce the results before [5]. Himmelreich presented her work a successful use of $\mathrm{CO}_{2}$ as an alternative building block for various plastics, replacing a proportion of the petrochemical precursors otherwise used [6].

The specific data need of the producers, can thus be satisfied with the provision of a LCI on WEEE; where material efficiency is linked to the different life-cycle stages: raw material extraction, manufacturing, end-of-life [7].

Specific end-user LCAs and well defined average scenarios are recommended by Heslouin et al. [8] to improve the global environmental footprint. The work also highlights how far we have to go in the collection of data for users' behaviour.

Energy savings of the building sector can be enhanced in the future if LCA studies are accompanying the development of multi-functional energy-efficient windows or façades, designed to produce energy from sunlight and to store heating energy [10].

\section{References}

1. Oberschelp C, Pfister S, Hellweg S, Reduction of site-specific electricity generation particulate matter impacts in China, Life Cycle Management Conference, Luxembourg, 2017.

2. Lévová T, Valsasina L, Geographical resolution of LCI data on electricity production - the level of detail needed, Life Cycle Management Conference, Luxembourg, 2017.

3. Chatzisideris M.D, Espinosa N, Laurent A, Krebs F.C, Quantifying the importance of comprehensive life cycle and impact coverage for photovoltaic systems, Life Cycle Management Conference, Luxembourg, 2017.

4. Weyand S, Glogic E, Sonnemann G., Schebek L,Young S.B, Consequential life cycle assessment of an organic photovoltaic portable solar charger applied in the context of European electricity mixes, Life Cycle Management Conference, Luxembourg, 2017.

5. Heo Y, Rana S, Suh Y, Life Cycle Assessment of a Mobile Charger containing Recycled Plastics, Life Cycle Management Conference, Luxembourg, 2017.

6. Himmelreich B, A Dream comes true- Use of $\mathrm{CO}_{2}$ for the production of plastics, Life Cycle Management Conference, Luxembourg, 2017.

7. Van Nieuwenhuyse T, Assimo, P, Morice L, Lesage R, Hugrel C, Palluau M, Osset P, An innovative LCI Database on WEEE management, Life Cycle Management Conference, Luxembourg, 2017.

8. Heslouin C, Pourcheresse L, Stumpf A, Bernardet V.P, Cornier A, Perry N, Is it useful to improve modeling of usage scenario to improve the environmental footprint of energy consumption product? Life Cycle Management Conference, Luxembourg, 2017. 
9. A European strategy for smart, sustainable and inclusive growth, 2010, Brussels: EUROPEAN COMMISSION.

10. Schmidt A, Su L, Fraass M, Wondraczek L, Design accompanying Life Cycle Assessment for the development of new energy-efficient window concepts, Life Cycle Management Conference, Luxembourg, 2017.

Open Access This chapter is licensed under the terms of the Creative Commons Attribution 4.0 International License (http://creativecommons.org/licenses/by/4.0/), which permits use, sharing, adaptation, distribution and reproduction in any medium or format, as long as you give appropriate credit to the original author(s) and the source, provide a link to the Creative Commons license and indicate if changes were made.

The images or other third party material in this chapter are included in the chapter's Creative Commons license, unless indicated otherwise in a credit line to the material. If material is not included in the chapter's Creative Commons license and your intended use is not permitted by statutory regulation or exceeds the permitted use, you will need to obtain permission directly from the copyright holder.

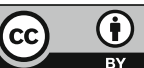

